\title{
Multiredox Heterometallic Carbosilane Dendrimers
}

\author{
Magdalena Zamora, Beatriz Alonso, César Pastor and Isabel Cuadrado* \\ Departamento de Química Inorgánica, Facultad de Ciencias, Universidad Autónoma de Madrid, \\ Cantoblanco, 29049, Madrid, Spain
}

\section{Supporting Information}

\section{Modification of Electrode Surfaces with ferrocenyl dendrimers.}

The ferrocenyl dendrimers $\mathbf{8}$ and $\mathbf{9}$ were electrodeposited in their oxidized forms onto carbon-glassy and platinum electrode surfaces, either by controlled potential electrolysis at $0.6 \mathrm{~V}$, or by repeated scanning the potential (at $100 \mathrm{mV} / \mathrm{s}$ ) between -0.2 and $+1.2 \mathrm{~V}$ vs $\mathrm{SCE}$ in degassed $\mathrm{CH}_{2} \mathrm{Cl}_{2}$ solutions of the corresponding dendrimer with $0.1 \mathrm{M} n-\mathrm{Bu}_{4} \mathrm{NPF}_{6}$. Therefore, the amount of the electrodeposited dendritic material can be controlled through the time interval during which the potential or the number of scans was held fixed.

The electrodes thus coated were removed from the dendrimer-containing $\mathrm{CH}_{2} \mathrm{Cl}_{2}$ solution, rinsed with $\mathrm{CH}_{2} \mathrm{Cl}_{2}$ to remove any adhering solution and dried in air. The electrochemical behavior of films of the polyferrocenyl dendrimers 8 and $\mathbf{9}$ was studied by cyclic voltammetry in fresh $\mathrm{CH}_{2} \mathrm{Cl}_{2}$ solution containing only supporting electrolyte, in which both redox forms of $\mathbf{8}$ and $\mathbf{9}$ are insoluble.

The total surface electroactive coverage of ferrocenyl sites in the film, $\Gamma\left(\mathrm{mol} \mathrm{cm}^{-2}\right)$, was determined from the integration of the area under the cyclic voltammetric wave (i.e. the charge). 


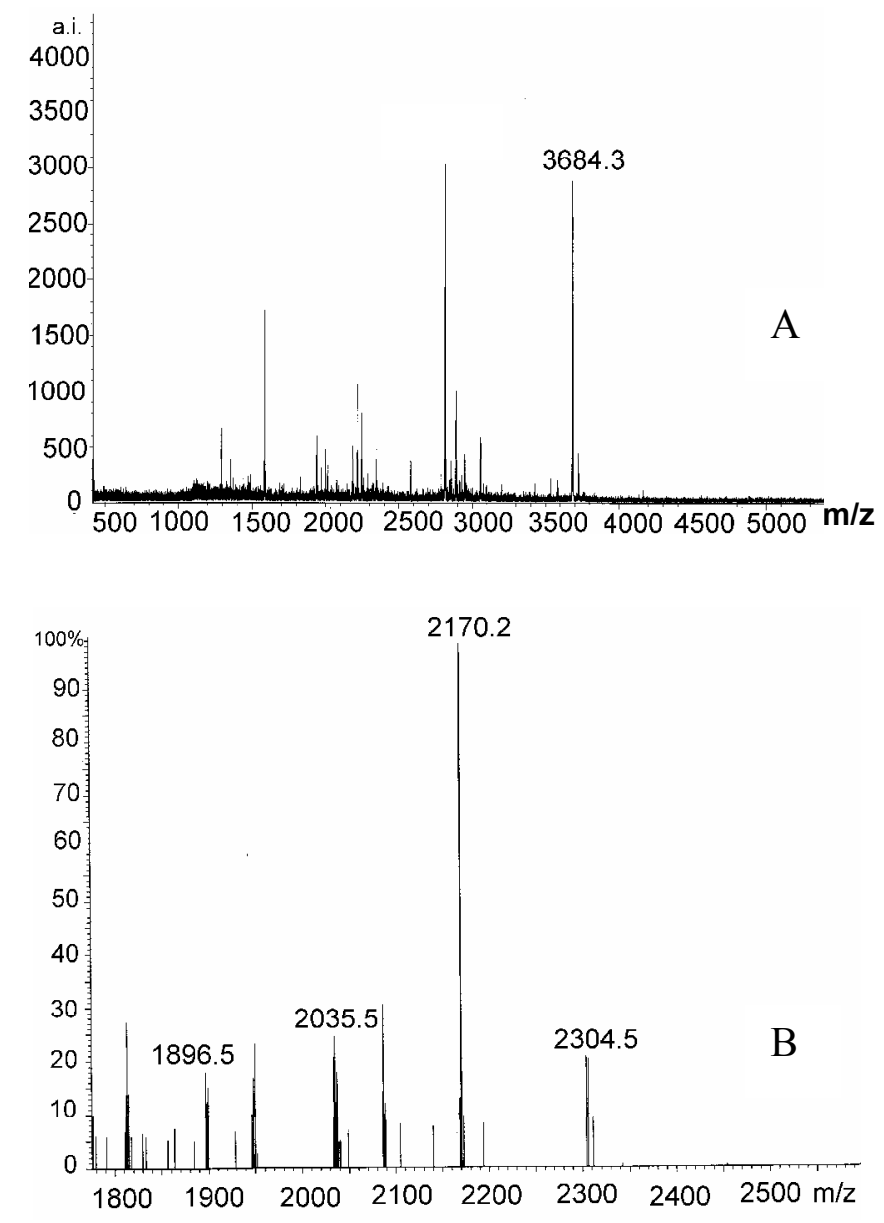

Figure 1.- Representative mass spectra of the homo- and heterometallic dendrimers: (A) MALDITOF-MS spectrum of dendrimer 8 and (B) FAB-MS spectrum of the heterometallic dendrimer 7. 

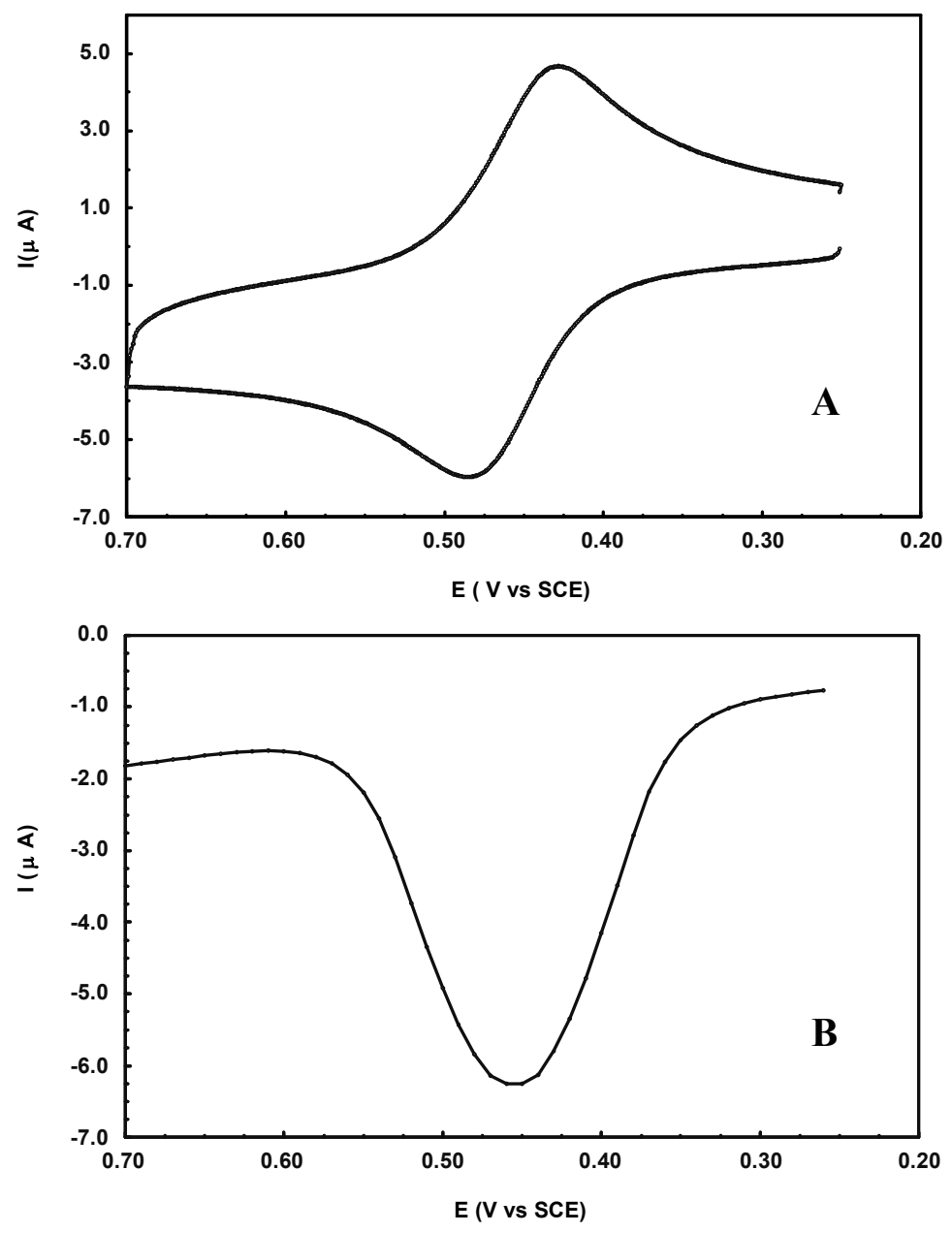

Figure 2.- Cyclic voltammogram (A) and differential pulse voltammogram (B) of dendrimer 9 in $\mathrm{CH}_{2} \mathrm{Cl}_{2} / n-\mathrm{Bu}_{4} \mathrm{NPF}_{6}$. 